\title{
ДИФФЕРЕНЦИАЦИЯ УРОВНЯ ЖИЗНИ НАСЕЛЕНИЯ МУНИЦИПАЛЬНЫХ ОБРАЗОВАНИЙ ВОРОНЕЖСКОЙ ОБЛАСТИ
}

\author{
И. В. Сафонова, Н. В. Яковенко, М. В. Деревягина \\ Воронежский государственный университет, Россия \\ Поступила в редакциию 11 ноября 2018 г.
}

\begin{abstract}
Аннотация: В статье на основе трех методов: суммы мест, индексной оценки и группировки с использованием многомерной средней показана дифференциация уровня жизни населения муниципальных образований Воронежской области.
\end{abstract}

Ключевые слова: дифференциация, уровень жизни населения, муниципальные образования, Воронежская область.

Abstract: On the basis of three methods: the sum of places, index estimation and grouping with the use of multidimensional average, the differentiation of the living standard of the population in the Voronezh region municipalities has been shown.

Key words: differentiation, living standards of the population, municipalities, Voronezh region.

Уровень жизни населения - наиболее сложная, многоплановая социально-экономическая категория. Среди многих ученых, занимающихся проблемами изучения уровня жизни населения следует отметить Л.И. Абалкина, В.И. Гурьева, Т.И. Заславскую, Н. М. Римашевскую, В. А. Ядова и др. Непосредственно развитием методики оценки уровня жизни населения занимаются такие ученые как Е. Г. Анимица, В. Н. Бобков, О. А. Веклич, Н.А. Денисов, В.М. Жеребин, Н. Землянская, Н. В. Зубаревич, П.С. Мстиславский и др. На настоящий момент существует множество подходов к оценке уровня жизни населения регионов $[1,5,6]$.

Рассмотрим три из них - метод суммы мест, метод индексной оценки и метод группировки на основе многомерной средней, и проведем на их основе дифференциацию уровня жизни населения муниципальных образований Воронежской области. Отбор показателей для исследования осуществлялся с учетом одного и самого важного принципа - доступность в статистической базе. Выбор данных был определен их наличием, но за исключением дублирующих показателей [2].

Были отобраны наиболее обобщенные показатели: уровень занятости, \%; уровень безработицы, $\%$; среднемесячная номинальная начисленная заработная плата работающих, руб.; наличие легко-

(С Сафонова И. В., Яковенко Н. В., Деревягина М. В., 2019 вых автомобилей в личной собственности, шт.; число собственных легковых автомобилей на 1000 человек населения, шт.; общая площадь жилых помещений, в среднем на одного жителя, м²; число зарегистрированных преступлений на 100000 человек населения, шт.; ввод в действие общей площади жилых домов на 1000 чел. населе-

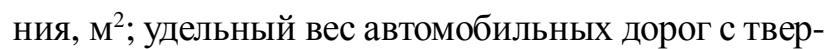
дым покрытием в общей протяженности автомобильных дорог общего пользования, \%; оборот розничной торговли на душу населения, тыс. руб. [3].

Метод суммы мест. Суть метода заключается в том, что по значению каждого из анализируемых социально-экономических показателей происходит ранжирование рассматриваемых муниципальных образований Воронежской области, от меньшего значения к большему. Далее, позиции, занимаемые каждым муниципальным образованием, суммируются и располагаются по убыванию. Чем более лидирующую позицию занимает район по тому или иному показателю, тем меньше в итоге сумма мест данного района.

Главный принцип при проведении расчетов ранжирование муниципальных образований выстраивается от большего к меньшему (для показателей, имеющих прямую зависимость от роста уровня жизни населения), и, наоборот - для показателей, увеличение значения которых указывает на снижение уровня жизни (например, уровень 


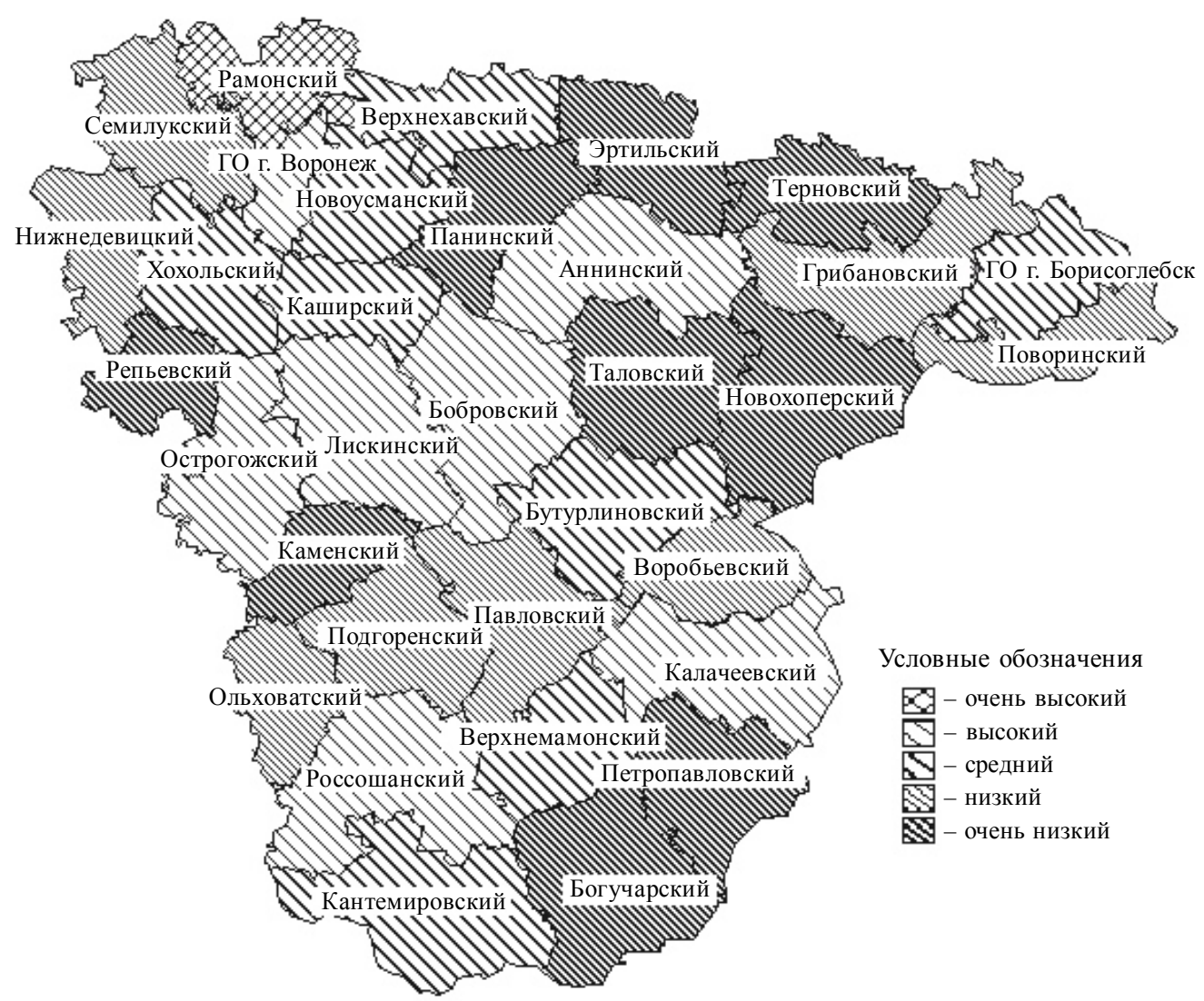

Puc. 1. Дифференциация муниципальных образований Воронежской области по уровню жизни населения методом суммы мест (составлено по [3])

безработицы, число зарегистрированных преступлений и т.п.) - от меньшего значения к большему.

По результатам расчетов можно утверждать, что муниципальные образования могут занимать разные места в рейтинге, причем сочетание первого и последнего места - не исключение. В результате проведенного анализа социально-экономических показателей муниципальных образований Воронежской области по методу суммы мест условно можно выделить 5 групп районов, различающихся по уровню жизни (рис. 1).

1 группа - очень высокий уровень жизни, сумма мест менее 100. К данной группе на настоящий момент можно отнести только Рамонский район.

2 группа - высокий уровень жизни, объединяет 8 муниципальных образований с суммой мест от 100 до 150. К ним относятся: городской округ город Воронеж, Острогожский, Лискинский, Бобровский, Аннинский, Россошанский, Калачеевский муниципальные районы и городской округ город Нововоронеж.

Разница между административным образованием, относящимся к группе с очень высоким уровнем жизни (Рамонский район), и муниципальным образованием, занимающим лучшую позицию в группе с высоким уровнем жизни, составляет всего 19 единиц (например, городской округ город Воронеж).

3 группа - средний уровень жизни, с суммой мест от 150 до 200, в группу входят 6 муниципальных образований. Дифференциация между позициями районов, образующих эту группу, достаточно слабая.

4 группа - низкий уровень жизни, объединяющая 8 муниципальных образваний с суммой мест более 200. К ним относятся: Семилукский, Ольховатский, Подгоренский, Воробьевский, Нижнедевицкий, Грибановский, Поворинский муниципальные районы. Худший результат показывает Павловский район с показателем 237.

5 группа-очень низкий уровень жизни. К этой группе относится 9 муниципальных образований: Репьевский, Каменский, Панинский, Эртильский, Терновский, Новохоперский, Петропавловский, Таловский и Богучарский муниципальные районы.

Индексный метод. Индекс представляет собой относительную величину, показывающую во сколько раз уровень изучаемого явления в опреде- 


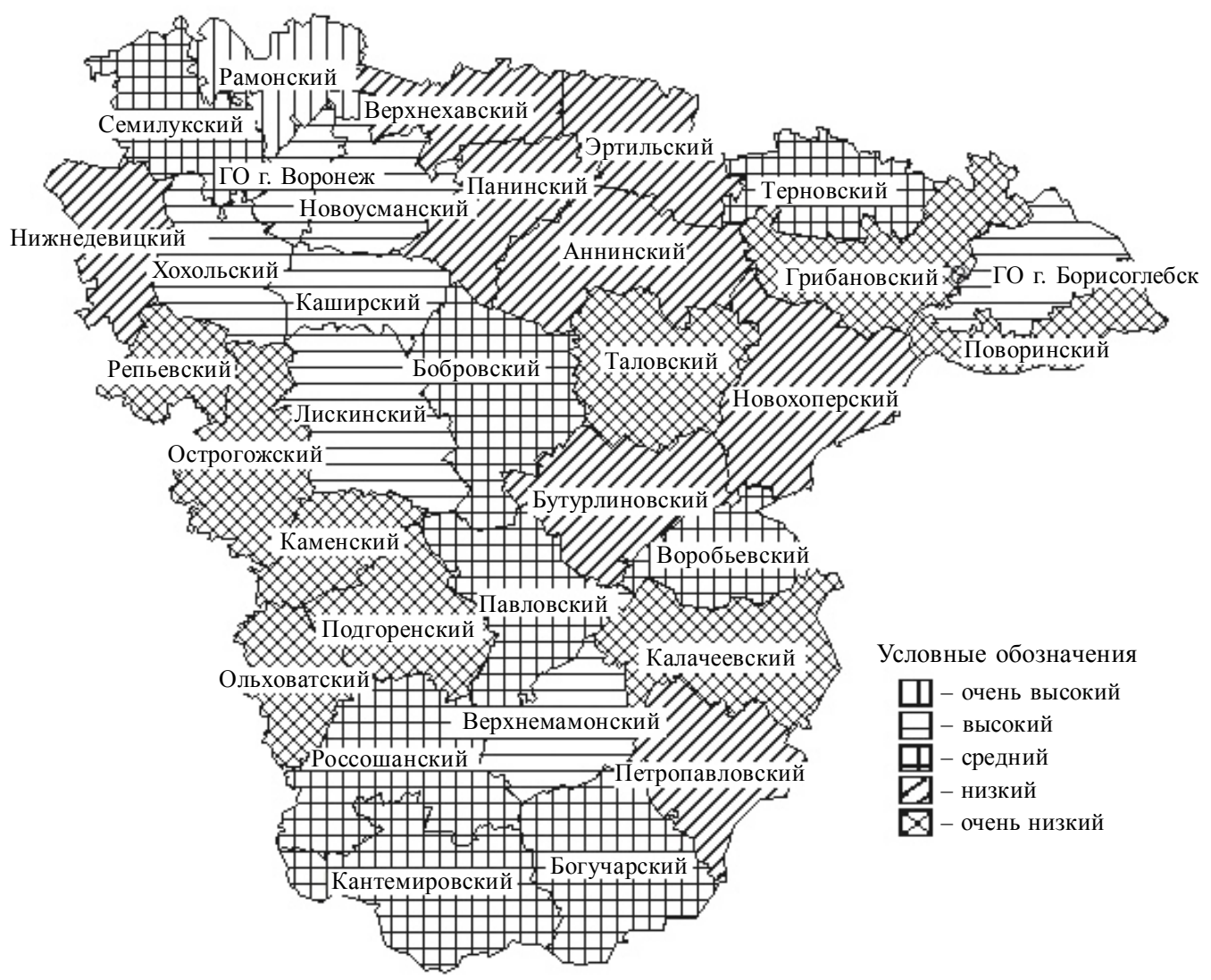

Puc. 2. Дифференциация муниципальных образований Воронежской области по уровню жизни населения индексным методом (составлено по [3])

ленных условиях отличается от уровня этого же явления в других заданных условиях. Поэтому выделяется различие во времени - индексы динамики, и различие в пространстве - территориальные индексы. Для получения балльных оценок строится шкала диапазонов реальных значений по каждому из социально-экономических показателей всех муниципальных образований Воронежской области. Получаемые данные разбиваются на 100 равных интервалов, каждый из которых имеет определенное количество баллов, равное номеру интервала (от 1 до 100).

Полученная сумма балльных оценок по всем показателям рассматриваемого муниципального образования - это и есть индекс социально-экономического благополучия населения (ИСЭБН) для данного образования. Затем проводится ранжирование полученных ИСЭБН по значениям от большего к меньшему - большее количество баллов определяет более высокое положение района в общем рейтинге, и наоборот.

По данной методике нами были получены индексы социально-экономического благополучия населения по 34 муниципальным образованиям
Воронежской области, на основании которых было выделено 5 групп районов (рис. 2).

Как можно отметить, и по этому методу к 1 группе с очень высоким уровнем жизни (ИСЭБН более 400), висчисляется только одно муниципальное образование - Рамонский район со значением ИСЭБН $=635$.

Метод группировки на основе многомерных средних. В рамках данного метода в каждом ряду социально-экономических показателей находится средняя арифметическая их значений. Эта средняя арифметическая принимается за $100 \%$ по данному социально-экономическому показателю. Далее, последовательно находится процент, который составляет фактическое значение каждого муниципального образования Воронежской области по тому или иному показателю. Данный метод дает возможность провести ранжирование муниципальных образований по уровню жизни населения, а также провести оценку различий в уровне жизни по значению многомерной средней.

В этом случае ранжирование проводится по убыванию (от большего к меньшему) [4, 5]. При помощи данного метода нами были получены зна- 


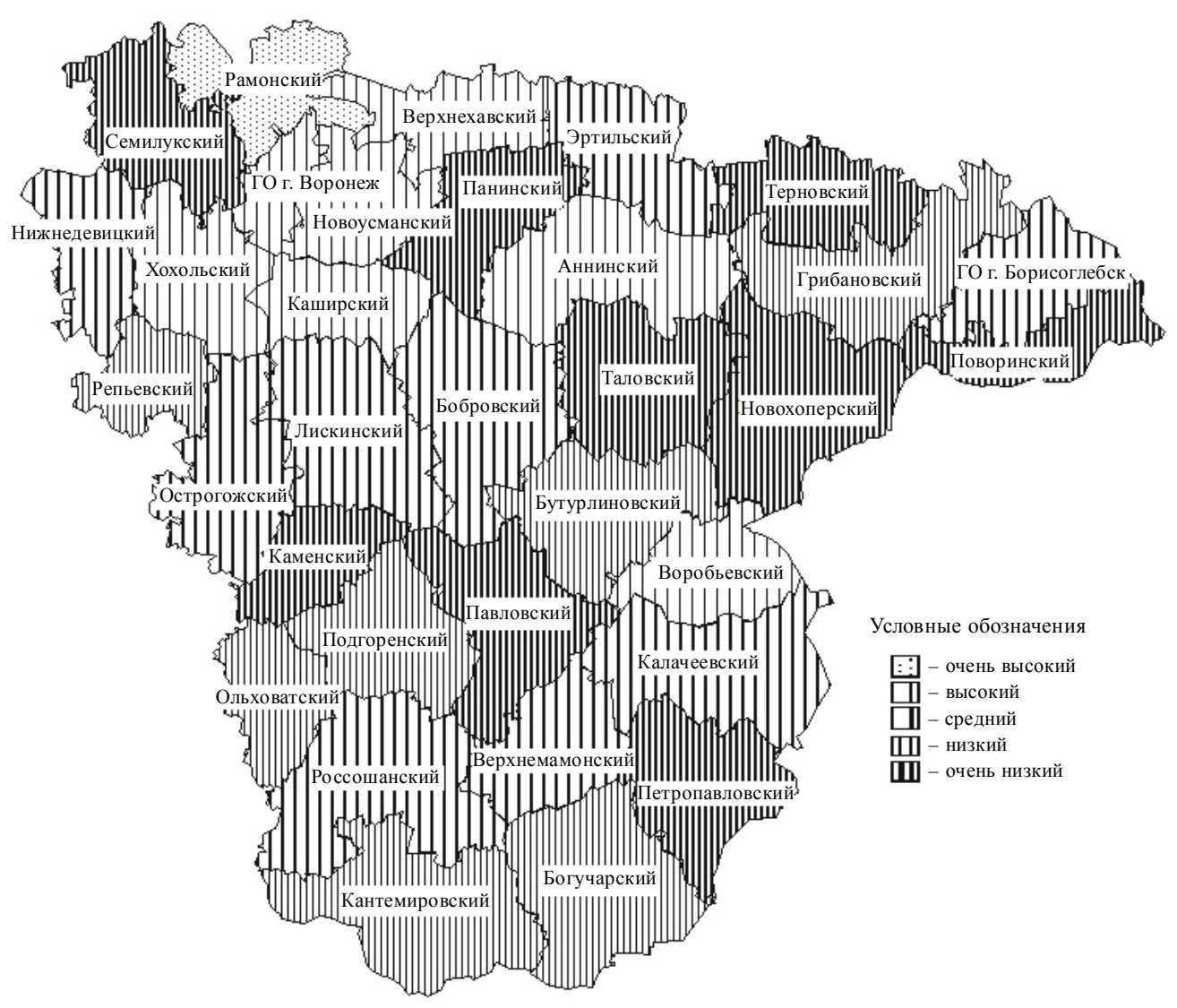

Puc. 3. Дифференциация муниципальных образований Воронежской области по уровню жизни населения методом группировки на основе многомерных средних (составлено по [3])

чения многомерной средней социально-экономического благополучия населения по 34 муниципальным образованиям Воронежской области, на основании которых было выделено 5 групп районов по уровню жизни населения (рис. 3).

Полученные результаты, как и в предыдущих случаях, подтверждают, что самый высокий уровень жизни населения наблюдается в Рамонском районе. Значение многомерной средней здесь равно более $300 \%$. А Каменский и Таловский муниципальные районы стабильно занимают последние позиции по уровню жизни населения при исчислении по 3 методам.

Дифференциация значений многомерной средней в 4 и 5 группах крайне слабая - муниципальные районы или набирают одинаковую сумму баллов, или значения соседствующих многомерных средних различаются всего на 1 балл.

Сравнение оценок муниципальных образований Воронежской области показывает, что не изменяются или изменяются незначительно результаты в 8 муниципальных образованиях - городские округа город Воронеж и город Нововоронеж, Каменский, Каширский, Новохоперский, Петро- павловский, Рамонский и Таловский районы. Однако ровную стабильную ситуацию показывают показатели Рамонского района, который занимает лидирующие позиции.

Очевидно, что при использовании каждого из методов исследования в результате выделяется пять групп, в которых объединяются муниципальные образования с разным уровнем жизни населения. В итоге можно все расчеты свести в сводную таблицу и рассмотреть соотношение составов групп в зависимости от примененного метода исследования (таблица).

Лидирующие позиции неизменны при использовании каждого из методов, при чем, как правило, отрыв от последующих групп муниципальных образований - существенный. В других группах дифференциация в зависимости от метода исследования более значительная. В особенности отличаются результаты исследования, проведенного по индексному методу (рис. 1) в сравнении с другими методами.

Данные различия обусловлены зачастую дифференциацией значений показателей, по которым проводится оценка в регионе - одно и тоже муни- 
Соотношение составов групп муниципальных образований в зависимости от методов исследования

\begin{tabular}{|c|c|c|c|c|}
\hline \multicolumn{5}{|c|}{ Метод суммы мест } \\
\hline $\begin{array}{c}\text { Очень } \\
\text { высокое }\end{array}$ & Высокое & Среднее & Низкое & Очень низкое \\
\hline \multirow[t]{9}{*}{ Рамонский } & Воронеж & Борисоглебск & Семилукский & Репьевский \\
\hline & Острогожский & Хохольский & Ольховатский & Каменский \\
\hline & Лискинский & Каширский & Подгоренский & Панинский \\
\hline & Бобровский & Новоусманский & Павловский & Эртильский \\
\hline & Аннинский & Верхнехавский & Воробьевский & Терновский \\
\hline & Россошанский & Кантемировский & Нижнедевицкий & Новохоперский \\
\hline & Калачеевский & Верхнемамонский & Грибановский & Петропавловский \\
\hline & Нововоронеж & Бутурлиновский & Поворинский & Таловский \\
\hline & & & & Богучарский \\
\hline \multicolumn{5}{|c|}{ Индексный метод } \\
\hline \multirow[t]{9}{*}{ Рамонский } & Воронеж & Семилукский & Нижнедевицкий & Репьевский \\
\hline & Борисоглебск & Бобровский & Панинский & Острогожский \\
\hline & Хохольский & Терновский & Эртильский & Каменский \\
\hline & Лискинский & Россошанский & Аннинский & Подгоренский \\
\hline & Каширский & Павловский & Верхнехавский & Ольховатский \\
\hline & Новоусманский & Воробьевский & Новохоперский & Таловский \\
\hline & Верхнемамонский & Кантемировский & Бутурлиновский & Поворинский \\
\hline & Нововоронеж & Богучарский & Петропавловский & Грибановский \\
\hline & & & & Калачеевский \\
\hline \multicolumn{5}{|c|}{ Метод многомерных средних } \\
\hline \multirow[t]{9}{*}{ Рамонский } & Воронеж & Борисоглебск & Репьевский & Семилукский \\
\hline & Хохольский & Нижнедевицкий & Ольховатский & Каменский \\
\hline & Каширский & Острогожский & Подгоренский & Панинский \\
\hline & Новоусманский & Лискинский & Бутурлиновский & Павловский \\
\hline & Верхнехавский & Бобровский & Эртильский & Новохоперский \\
\hline & Аннинский & Россошанский & Грибановский & Терновский \\
\hline & Воробьевский & Верхнемамонский & Кантемировский & Поворинский \\
\hline & Нововоронеж & Калачеевский & Богучарский & Петропавловский \\
\hline & & & & Таловский \\
\hline
\end{tabular}

ципальное образование может занимать лидирующую позицию по определенному показателю, но в то же время быть аутсайдером по другому показателю.

\section{СПИСОК ЛИТЕРАТУРЫ}

1. Деревягина М. В. Современные миграционные процессы в Воронежской области / М. В. Деревягина, Н. В. Яковенко // Вестник Воронежского государственного университета. Сер. География. Геоэкология. - 2017. - № 2. - С. 110-112.

2. Наухацкая Т. Я. Анализ различий в уровне жизни населения федеральных округов России на основеобобщающих критериев / Т. Я. Наухацкая // Статистика в современном мире: методы, модели, инструменты : материалы Международной научно-практической. конференции, посвященной 90-летию со дня рождения В. С. Князевского. - Ростов-на-Дону : Ростовский го- сударственный экономический университет (РИНХ), 2013. - С. 124-129.

3. Показатели экономического и социального развития городских округов и муниципальных районов Воронежской области : статистический сборник. - Воронеж, 2016. - $183 \mathrm{c}$.

4. Яковенко Н. В. Теоретико-методологические подходы к исследованию депрессивных регионов России / Н. В. Яковенко, Ю. В. Поросенков // Вестник Воронежского государственного университета. Сер. География. Геоэкология. - 2013. - № 2. - С. 10-21.

5. Яковенко Н. В. Теоретико-методические аспекты оценки социально-экологического благополучия населения в урбанизированной среде / Н. В. Яковенко, И. В. Сафонова // Современная экология: образование, наука, практика : материалы международной научнопрактической конференции. - Воронеж, 2017. - Т. 2. C. $127-131$. 
6. Яковенко Н. В. «Качество жизни населения» как научная категория демографии / Н. В. Яковенко // Экология урбанизированных территорий. - 2007. - № 1. C. 41-46.

\section{REFERENCES}

1. Derevyagina M. V. Sovremennyye migratsionnyye protsessy v Voronezhskoy oblasti / M. V. Derevyagina, N. V. YAkovenko// Vestnik Voronezhskogo gosudarstvennogo universiteta. Ser. Geografiya. Geoekologiya. - 2017. - № 2. - S. 110-112.

2. Naukhatskaya T. YA. Analiz razlichiy v urovne zhizni naseleniya federal'nykh okrugov Rossii na osnoveobobshchayushchikh kriteriyev / T. YA. Naukhatskaya // Statistika v sovremennom mire: metody, modeli, instrumenty : materialy Mezhdunarodnoy nauchno-prakticheskoy. konferentsii, posvyashchennoy 90-letiyu so dnya rozhdeniya V. S. Knyazevskogo. - Rostov-na-Donu : Rostovskiy gosudarstvennyy ekonomicheskiy universitet (RINKH), 2013. - S. 124-129.

\section{Сафонова Ирина Вячеславовна}

аспирант кафедры социально-экономической географии и регионоведения факультета географии, геоэкологии и туризма Воронежского государственного университета, г. Воронеж, т. +7 (473) 266-56-54

Яковенко Наталия Владимировна доктор географических наук, профессор, заведующий кафедрой социально-экономической географии и регионоведения факультета географии, геоэкологии и туризма Воронежского государственного университета, г. Воронеж, т. +7 (473) 266-56-54, E-mail: n.v.yakovenko71@gmail.com

Деревягина Мария Владимировна преподаватель кафедры социально-экономической географии и регионоведения факультета географии, геоэкологии и туризма Воронежского государственного университета, г. Воронеж, т. +7 (473) 266-56-54, E-mail: m derevyagina@mail.ru
3. Pokazateli ekonomicheskogo i sotsial'nogo razvitiya gorodskikh okrugov i munitsipal'nykh rayonov Voronezhskoy oblasti : statisticheskiy sbornik. - Voronezh, 2016. $-183 \mathrm{~s}$.

4. YAkovenko N. V. Teoretiko-metodologicheskiye podkhody $\mathrm{k}$ issledovaniyu depressivnykh regionov Rossii / N. V. YAkovenko, YU. V. Porosenkov // Vestnik Voronezhskogo gosudarstvennogo universiteta. Ser. Geografiya. Geoekologiya. - 2013. - № 2. - S. 10-21.

5. YAkovenko N. V. Teoretiko-metodicheskiye aspekty otsenki sotsial'no-ekologicheskogo blagopoluchiya naseleniya v urbanizirovannoy srede / N. V. YAkovenko, I. V. Safonova // Sovremennaya ekologiya: obrazovaniye, nauka, praktika : materialy mezhdunarodnoy nauchno-prakticheskoy konferentsii. - Voronezh, 2017. - T. 2. - S. 127131.

6. YAkovenko N. V. «Kachestvo zhizni naseleniya» kak nauchnaya kategoriya demografii / N. V. YAkovenko // Ekologiya urbanizirovannykh territoriy. - 2007. - № 1. S. 41-46.

Safonova Irina Vyacheslavovna

Postgraduate of the Department of Social and Economic geography and Regional Studies, Faculty of Geography, Geoecology and Tourism, Voronezh State University, Voronezh, tel. +7 (473) 266-56-54

Yakovenko Nataliya Vladimirovna

Doctor of Geographical Sciences, Professor, Head of the Department of Social and Economic geography and Regional Studies, Faculty of Geography, Geoecology and Tourism, Voronezh State University, Voronezh, tel. +7(473)266-56-54, E-mail: n.v.yakovenko71@ gmail.com

Derevyagina Maria Vladimirovna

Lecturer of the Department of Social and Economic Geography and Regional Studies, Faculty of Geography, Geoecology and Tourism, Voronezh State University, Voronezh, tel. +7 (473) 266-56-54, E-mail: m_derevyagina@mail.ru 